Check for updates

Cite this: DOI: 10.1039/d0mt00108b

Received 24th April 2020,

Accepted 24th July 2020

DOI: $10.1039 / \mathrm{d} 0 \mathrm{mt} 00108 \mathrm{~b}$

rsc.li/metallomics

\section{Zinc induced structural changes in the intrinsically disordered BDNF Met prodomain confer synaptic elimination $\dagger$}

\author{
Jing Wang, $\stackrel{\ddagger}{\ddagger}^{a}$ Agustin Anastasia, $\ddagger^{\text {bc }}$ Henrietta Bains, ${ }^{\text {ac }}$ Joanna I. Giza, (D) ${ }^{d}$ \\ David G. Clossey, ${ }^{c}$ Jingjing Deng, ${ }^{e}$ Thomas A. Neubert, (iD ${ }^{f}$ William J. Rice, (iD ${ }^{f}$ \\ Francis S. Lee, ${ }^{9}$ Barbara L. Hempstead ${ }^{\star c}$ and Clay Bracken (D) ${ }^{a}$
}

Human brain derived neurotrophic factor (BDNF) encodes a protein product consisting of a C-terminal mature domain (mature BDNF) and an N-terminal prodomain, which is an intrinsically disordered protein. A common single nucleotide polymorphism in humans results in a methionine substitution for valine at position 66 of the prodomain, and is associated with memory deficits, depression and anxiety disorders. The BDNF Met66 prodomain, but not the Val66 prodomain, promotes rapid structural remodeling of hippocampal neurons' growth cones and dendritic spines by interacting directly with the SorCS2 receptor. While it has been reported that the Met66 and Val66 prodomains exhibit only modest differences in structural propensities in the apo state, here we show that Val66 and Met66 prodomains differentially bind zinc ( $\mathrm{Zn})$. $\mathrm{Zn}^{2+}$ binds with higher affinity and more broadly impacts residues on the Met66 prodomain compared to the Val66 prodomain as shown by NMR and ITC. $\mathrm{Zn}^{2+}$ binding to the Met66 and Val66 prodomains results in distinct conformational and macroscopic differences observed by NMR, light scattering and cryoEM. To determine if $\mathrm{Zn}^{2+}$ mediated conformational change in the Met66 prodomain is required for biological effect, we mutated His40, a $\mathrm{Zn}^{2+}$ binding site, and observed a loss of Met66 prodomain bioactivity. As the His40 site is distant from the known region of the prodomain involved in receptor binding, we suggest that Met66 prodomain bioactivity involves His40 mediated stabilization of the multimeric structure. Our results point to the necessity of a $\mathrm{Zn}^{2+}$-mediated higher order molecular assembly of the Met66 prodomain to mediate neuronal remodeling.
Significance to metallomics

The brain derived neurotrophic factor (BDNF) Val66Met variant is a significant risk factor in cognitive decline and psychiatric disorders. The BDNF prodomain region and mature BDNF are expressed in the hippocampus and amygdala, brain regions that accumulate zinc. Zinc, but not other cations present in the synapse, induce structural differences between the Val66 and Met66 prodomains, at physiologically relevant concentrations. Our results suggest that zinc binding confers synaptic remodeling activity to the Met66 prodomain isoform.

\section{Introduction}

Neurotrophins, a family of conserved growth factors, were initially identified by their ability to confer neuronal survival and differentiation during development. Of the four neurotrophins found in humans, brain derived neurotrophic factor (BDNF) is the most extensively studied and plays critical roles modulating activity-dependent synaptic plasticity, cell migration, dendritic arborization and even cell death. ${ }^{1-4}$ These diverse responses are regulated by utilization of different protein products of the $b d n f$ gene. ${ }^{5}$ BDNF is translated as a precursor, proBDNF $(\sim 25.7 \mathrm{kD}$, aa 1-247), encoding an intrinsically disordered $\mathrm{N}$-terminal prodomain (aa 19-128) and a structured C-terminal mature domain which dimerizes (aa 129-247) (mature BDNF or mBDNF) (Fig. 1A). Proteolytic processing of proBDNF results in the release of dimeric mBDNF and monomeric prodomain. In the adult brain, the prodomain and mBDNF are the predominant

\footnotetext{
${ }^{a}$ Weill Cornell Medicine, Department of Biochemistry, New York, NY, USA. E-mail: wcb2001@med.cornell.edu; Tel: +212 746-6473

${ }^{b}$ Instituto Ferreyra (INIMEC-CONICET-Universidad Nacional de Córdoba), Córdoba, Argentina

${ }^{c}$ Weill Cornell Medicine, Department of Medicine, New York, NY, USA. E-mail: blhempst@med.cornell.edu; Tel: +212 746-6215

${ }^{d}$ Department of Science, Borough of Manhattan Community College, York, New York, NY, USA

${ }^{e}$ Skirball Institute and Department of Cell Biology, New York University School of Medicine, New York, NY, USA

${ }^{f}$ New York University Langone Health, New York, NY, USA

${ }^{g}$ Weill Cornell Medicine, Department of Psychiatry, New York, NY, USA

$\dagger$ Electronic supplementary information (ESI) available. See DOI: 10.1039/d0mt00108b

\$ These authors contributed equally to this work.
} 


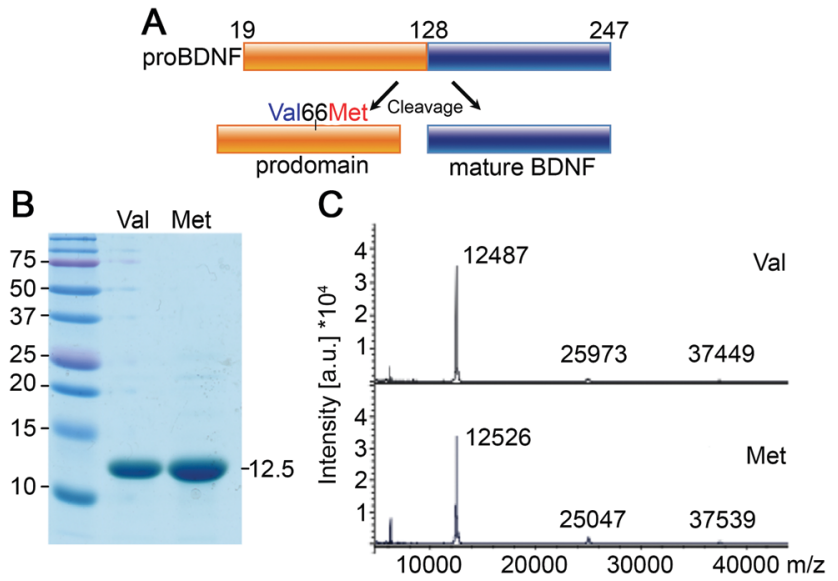

Fig. 1 (A) Schematic of the proBDNF protein ( 25.7 kD, aa 19-247), encoding an intrinsically disordered $\mathrm{N}$-terminal prodomain (orange) ( $12.5 \mathrm{kD}$, aa 19-128) and a structured C-terminal mature domain, which forms non-covalent dimers ( $13.5 \mathrm{kD}$ aa 129-247) (mature BDNF or mBDNF). (B) Protein purity analysis by using 15\% SDS-Page gels of full length Val66-prodomain and Met66-prodomain at $17 \mu \mathrm{g}$ and $28 \mu \mathrm{g}$ protein loads respectively. (C) Mass spectrometry analysis using an Bruker Autoflex MALDI-TOF, (Bruker Daltonics) mass spectrometer for intact mass detection of unlabeled Val66 and Met66 prodomains clearly distinguishes the 32 atomic mass unit (amu) difference between Val and Met isoforms. The observed monomer peaks are within instrumental error of the expected molecular weights for Val and Met prodomains of 12492 MW and 12524 MW respectively.

isoforms found. ${ }^{6}$ The $\mathrm{mBDNF}$ protein activates TrkB to promote neuronal survival, growth and development. In contrast, proBDNF binds to a complex of p75NTR and SorCS2 (or Sortilin), which mediates cell death, dendritic remodeling and long term depression (LTD). ${ }^{4,7}$ The prodomain together with cleaved mBDNF are co-secreted at the synapse following repeated neuronal stimulation and exposed to an environment that contains cations, including zinc (Zn). ${ }^{6}$ The prodomain region contains a single nucleotide polymorphism, that results in a valine to methionine amino acid change at position 66 (Val66-Met). The Met66 substitution is present in approximately $20 \%$ of the human population. ${ }^{9}$ Met66 carriers have increased susceptibility to develop anxiety disorders, depression, memory deficits, reduced hippocampal volume and impaired recovery after traumatic brain injury. ${ }^{9-14}$ Despite the biological significance of the Val66Met polymorphism, the potential impact of metal-induced structural change upon the secreted prodomain of BDNF has not been examined.

The bioactivity of the Met66 prodomain results from its interactions with SorCS2, a Vsp10 domain protein which is expressed on the plasma membrane. The activity of this ligand also requires that SorCS2 co-associates with the $\mathrm{p} 75^{\mathrm{NTR}}$ receptor, a member of the tumor necrosis factor superfamily. ${ }^{6}$ Both proteins are expressed on the postsynaptic region of dendritic spines. Only the Met66 prodomain, but not the Val66 isoform induces acute collapse of mature dendritic spines. ${ }^{15}$ Both the Met66 and Val66 isoforms are intrinsically disordered and exhibit limited structural differences in the region of the Val66Met substitution, and the differences in the interaction with SorCS2 are modest ${ }^{6}$ in the absence of cations and unlikely to account for the dramatic differences in biological effects. This suggests that other co-factors may be required to induce structural differences. $\mathrm{MBDNF}$ and the prodomain are co-secreted from dense core vesicles (DCV) into the synaptic cleft, ${ }^{16}$ coordinately with synaptic vesicle exocytosis in response to sustained neuronal excitation. Thus the prodomain is exposed to micromolar to millimolar concentrations of divalent metals $\mathrm{Ca}^{2+}, \mathrm{Mg}^{2+}$ and $\mathrm{Zn}^{2+}$ present in the synaptic cleft $^{17-20}$ prior to engaging SorCS2.

Here we examine the potential role of physiologically relevant concentrations of divalent cations to induce structural changes in the Met66 vs. Val66 variants of the prodomain which could lead to selective bioactivity of the Met66 prodomain. We demonstrate that both Val66 and Met66 prodomains interact with $\mathrm{Zn}^{2+}$ and induce structural differences as determined using NMR. Furthermore, $\mathrm{Zn}^{2+}$ binding results in differences in macroscopic oligomerization of the Val66 as compared to the Met66 prodomain, as determined by cryo-electron microscopy (cryoEM). We show that $\mathrm{Zn}^{2+}$ interacts with the prodomain His40 to induce intermolecular association. Moreover, we demonstrate that mutation of His40 blocks the prodomain macromolecular structural assembly and abrogates the Met66 prodomain's degenerative bioactivity. Our results identify the unique actions of $\mathrm{Zn}^{2+}$ to induce structural changes in this intrinsically disordered protein, and suggest differences that contribute to the acquisition of bioactivity in the Met prodomain.

\section{Methods}

\section{Protein expression and purification}

The prodomain of BDNF was expressed in $E$. coli using a plasmid pET28 (Novagen, Madison, WI, USA) containing the gene of human BDNF prodomain Val66 or Met66 (amino acids 19-128 preceded by an N-terminal His-6-SUMO tag). ${ }^{21}$ Mutations were introduced into plasmids using Quick-Change mutagenesis (Stratagene) using forward (caggtgtgcggaccaaagg gactctggagag) and reverse (ctctccagagtcctttggtccgcacacctg) primers for introduction of His40Lys mutations, then confirmed by sequencing. Unlabeled and isotopically ${ }^{13} \mathrm{C}-{ }^{15} \mathrm{~N}$ or ${ }^{15} \mathrm{~N}$-labeled protein samples were expressed in $E$. coli using the Marley isotope exchange protocol ${ }^{22}$ Cells were lysed by sonication in $4 \mathrm{M}$ guanidine hydrochloride in the presence of $1 \mathrm{mM}$ PMSF and Sigma Protease inhibitor cocktail. Proteins were washed and initially purified on a Ni-NTA column (Invitrogen) followed by elution in $6 \mathrm{M}$ Urea, $300 \mathrm{mM}$ imidazole $\mathrm{pH} 6$. Protein was dialyzed against at $50 \mathrm{mM}$ Tris $100 \mathrm{mM} \mathrm{NaCl}$, pH 7.4 overnight. To remove the Sumo tag, the protein was incubated with the Ulp-1 protease for $1 \mathrm{~h}$ at room temperature, the untagged prodomain was separated from the His-tagged Sumo and His-tagged Ulp-1 by passage through a second Ni-NTA affinity column. All constructs were further purified by HPLC on a Vydac C18 column using a $0.1 \%$ formic acid, to $95 \%$ acetonitrile gradient. Purified fractions were lyophilized and stored at $-80{ }^{\circ} \mathrm{C}$. Sample purity was assessed, by SDS-PAGE 
and MALDI-TOF-MS (Fig. 1B and C). The prodomain concentrations were measured by UV absorbance using a calculated $\mathrm{OD}_{280}$ of 0.48 (ProtParam) or Bradford protein assay (BioRad).

\section{Mass spectrometry analysis}

The integrity of all samples was established by mass spectrometry (Fig. 1C). Prodomain isoforms were tested for high affinity $\mathrm{Zn}^{2+}$ binding using MALDI-TOF and direct infusion Electrospray Ionization (ESI) MS. Samples were dissolved in $10 \mathrm{mM}$ Tris buffer with $10 \mathrm{mM}$ piperazine $\mathrm{pH} 7.0$ at a protein concentration of $2.5 \mu \mathrm{M}$ in the presence of different concentrations of $\mathrm{ZnCl}_{2}: 0,10 \mu \mathrm{M}, 100 \mu \mathrm{M}, 1 \mathrm{mM}$. For MALDI-TOF $1 \mu \mathrm{l}$ samples were mixed with $1 \mu \mathrm{l}$ matrix $\left(20 \mathrm{mg} \mathrm{ml}^{-1}\right.$ sinapinic acid in $50 \%$ acetonitrile, $50 \%$ water with $0.1 \%$ trifluoroacetic acid). $1 \mu \mathrm{l}$ aliquots of the mixtures were deposited on a 384-well sample plate, allowed to air-dry, then analyzed by positive ion MALDI-TOF MS (Bruker Autoflex MALDI-TOF, Bruker Daltonics) in linear mode, or directly infused to LTQ-Orbitrap (Thermo Electron) mass spectrometer for intact mass detection.

\section{NMR spectroscopy}

Samples for NMR measurement were collected in $10 \mathrm{mM}$ Tris, $100 \mathrm{mM} \mathrm{NaCl}, 0.1 \mathrm{mM}$ DSS in $90 \% \mathrm{H}_{2} \mathrm{O} / 10 \% \mathrm{D}_{2} \mathrm{O}$ at $\mathrm{pH}$ 7.2. NMR data was collected $5{ }^{\circ} \mathrm{C}$ on Bruker AvanceHD spectrometers at $500 \mathrm{MHz}$ and $600 \mathrm{MHz}$ field strengths at Weill Cornell Medical College and confirmatory experiments at $800 \mathrm{MHz}$ and $900 \mathrm{MHz}$ field strengths at the NYSBC. NMR assignments were obtained by titration to the experimental conditions, starting with our previous prodomain NMR using well-resolved $2 \mathrm{D}^{15} \mathrm{~N}-\mathrm{HSQC}$ assigned resonance changes (Fig. S2A and B, ESI $\dagger$ ), ${ }^{23}$ (BMRB Entry 19357). Spectra were processed using TopSpin 3.2 (Bruker Corporation) or NMRPipe ${ }^{24}$ and analyzed using NMRFAM-Sparky. ${ }^{25} \mathrm{Zn}^{2+}$ binding was measured using $2 \mathrm{D}$ ${ }^{15} \mathrm{~N}-\mathrm{HSQC}$ NMR spectra collected in the presence or absence of sub-stoichiometric concentrations of $\mathrm{Zn}^{2+}$ buffered in $10 \mathrm{mM}$ Tris, $100 \mathrm{mM} \mathrm{NaCl}, \mathrm{pH} 7.2$ in $10 \% \mathrm{D}_{2} \mathrm{O} / 90 \% \mathrm{H}_{2} \mathrm{O}$. NMR ${ }^{15} \mathrm{~N}$ longitudinal $T_{1}$ with interleaved relaxation delays: 56, $505(2 \times)$, 838, 1171, 1839, $2170(2 \times)$ and $2835 \mathrm{~ms}$ and ${ }^{15} \mathrm{~N}$ transverse $T_{2}$ relaxation measurements with interleaved delays: $29.4,58.8(2 \times)$, 88.2, 147.0, $117.6(2 \times), 176.4,205.8 \mathrm{~ms}$, in randomized orders with duplicates points for statistical analysis as described in prior publications. $^{26-28}$ NMR relaxation decay curves were fitted to single exponential decay models to extract longitudinal $\left(R_{1}\right)$ and transverse $\left(R_{2}\right)$ relaxation rates using python scripts incorporated in NMRFAM-Sparky.

NMR translational diffusion measurements were collected on Bruker Avance IIIHD $600 \mathrm{MHz}$ using bionomial gradients as previously described. ${ }^{6,29}$ Diffusion measurements were carried out at $5 \mathrm{C}$ using prodomain concentrations ranging from $8.8 \mu \mathrm{M}$ to $178 \mu \mathrm{M}$. Diffusion rates were referenced to 1,4 -dioxin using the hydrodynamic radius of $2.2 \AA^{30}$ or DSS with a hydrodynamic radius of $3.5 \AA$. The apparent hydrodynamic radius of the protein $\left(R_{\mathrm{h}}^{\text {prot }}\right)$ was calculated as $R_{\mathrm{h}}^{\text {prot }}=\left(R_{\mathrm{h}}^{\text {ref }}\right)\left(D_{\text {ref }}\right) / D_{\text {prot }}$, using the measured diffusion rates of the protein $\left(D_{\text {prot }}\right)$ measured with an internal reference molecule $\left(D_{\text {ref }}\right)$ of radius $\left(R_{\mathrm{h}}^{\text {ref }}\right) \cdot{ }^{30}$ Diffusion rates for Dioxin and sodium 2,2-dimethyl-2-silapentane-5-sulfonate (DSS) reference standard signals were found to be invariant under all prodomain concentrations (all $\leq 1 \mathrm{mg} \mathrm{ml}^{-1}$ ) tested.

\section{Turbidity measurements}

Changes in turbidity upon addition of $\mathrm{ZnCl}_{2}$ were measured using a Varian Cary 50-Bio UV-Vis spectrophotometer employing a $1 \mathrm{~cm}$ path length masked quartz cell. Metal cation mediated aggregation kinetics were initiated upon rapid mixing of equal volumes prodomain and $\mathrm{Zn}^{2+}$ solutions to give final concentrations ranging from 2 to $10 \mu \mathrm{M}$ prodomain and 10 to $100 \mu \mathrm{M}$ $\mathrm{ZnCl}_{2}$ chloride in $10 \mathrm{mM}$ Tris, $100 \mathrm{mM} \mathrm{NaCl}$ at $\mathrm{pH} 7.2$ in a volume of $250 \mu \mathrm{l}$, turbidity curves were repeated a minimum of 3 times. Turbidity kinetics of were followed at $600 \mathrm{~nm}$ with data collected at $2 \mathrm{~s}$ intervals for up to $20 \mathrm{~min}$ immediately following mixing. Aggregate dissociation kinetics were initiated upon fivefold dilution, dissociation changes were followed at $600 \mathrm{~nm}$ for up to $20 \mathrm{~min}$. The dead-time of mixing for both formation and dissociation kinetics ranged from approximately 5 to $10 \mathrm{~s}$. Dissociation curves were fitted to single or multiexponential kinetic models using Igor plot (WaveMetrics), with model selection was based on $F$-test statistical criterion.

\section{Isothermal titration calorimetry (ITC)}

For all ITC experiments, prodomain samples were loaded into separate dialysis chambers and exhaustively co-dialyzed into ITC buffer ( $100 \mathrm{mM} \mathrm{NaCl}, 10 \mathrm{mM}$ Tris $\mathrm{pH}$ 7.2), then centrifuged at $15000 \times g$ for $10 \mathrm{~min}$ then degassed for $10 \mathrm{~min}$ immediately prior to ITC data collection. ITC data was collected on a Nano ITC (TA instruments) at $10{ }^{\circ} \mathrm{C}$. The sample cell $(1 \mathrm{ml})$ containing $50 \mu \mathrm{M}$ prodomain was titrated with $1.5 \mathrm{mM} \mathrm{ZnCl}_{2}$ solutions using $5 \mu \mathrm{l}$ injections collected every $500 \mathrm{~s}$ with a stirring speed of $300 \mathrm{rpm}$. The measured protein data were baseline corrected using thermal heats obtained by $\mathrm{Zn}^{2+}$ titration into buffer, then fitted, using the Nano Analyze Software (TA Instruments). The values of dissociation constant $\left(K_{\mathrm{d}}\right)$ and enthalpy $(\Delta H)$ reported constitute averages of 3 experiments preformed under the identical conditions, data were fitted using single and two site binding models.

\section{Electron microscopy}

Cryo-EM samples were prepared on carbon coated Quantifoil $1.2 \mu \mathrm{m}$ holey copper grids, which were glow-charged immediately prior to application of $3 \mu \mathrm{l}$ of $20 \mu \mathrm{M}$ protein in the presence of $200 \mu \mathrm{M} \mathrm{ZnCl}{ }_{2}$ in $10 \mathrm{mM}$ Tris, $10 \mathrm{mM}$ Piperazine $100 \mathrm{mM} \mathrm{NaCl}$ at pH 7.0. Following application, the grids were blotted for $2 \mathrm{~s}$ then plunge frozen in liquid ethane using a Gatan cryoplunge-3. Images $(4 \mathrm{k} \times 4 \mathrm{k})$ were collected on a Tecnai-F20 at the NY Structural Biology Center operating at $200 \mathrm{kVA}$ at $62 \mathrm{k} \times$ magnification at final pixel size $1.4 \AA$.

\section{Hippocampal culture}

Animal care was provided by the Research Animal Resource Center (RARC) at Weill Cornell Medicine following instructions of the "Guide for the care and use of laboratory animals" (National Research Council, USA). The animal research was approved by the Institutional Animal Care and Use Committee 
(IACUC) of Weill Cornell. Dissociated cultures of primary hippocampal neurons were prepared from E18 embryos of pregnant C57BL/6 mice. Excised hippocampi were dissociated into cell suspension using pre-warmed papain (Worthington Biochemical Corporation, Lakewood, NJ, USA) containing Hank's Balanced Sodium Solution (HBSS) (GIBCO) supplemented with DNase I, $1.5 \mathrm{mM} \mathrm{CaCl}_{2}$, and $0.75 \mathrm{mM}$ EDTA at $37{ }^{\circ} \mathrm{C}$ for $20-25 \mathrm{~min}$. After trituration, the neurons were plated on $12 \mathrm{~mm}$ poly-L-lysine $\left(1 \mathrm{mg} \mathrm{m} \mathrm{m}^{-1}\right.$ in $\left.\mathrm{dH}_{2} \mathrm{O}\right)$-coated coverslips. Prior to plating, coverslips (Electron Microscopy Sciences, Hatfield, PA, USA) were pre-incubated in Neurobasal medium (Gibco, Grand Island, NY, USA), containing $1 \mathrm{mM}$ sodium pyruvate (Gibco), $6 \mathrm{mM}$ Glutamax (Gibco), 10\% fetal bovine serum, $0.5 \%$ glucose, and $50 \mu \mathrm{g} \mathrm{ml}{ }^{-1}$ ampicilin. Following 5-6 hours of recovery in serum and glucose, the media was replaced with Neurobasal medium with added B27 (Gibco), $1 \mathrm{mM}$ pyruvate (GIBCO), $2 \mathrm{mM}$ glutamine (Gibco), $50 \mu \mathrm{g} \mathrm{ml}$ ampicilin, and $4 \mu \mathrm{M}$ cytosine-1- $\beta$-D-arabinofuranoside. ${ }^{15,31}$ The cells were left in the incubator for 18-21 days with occasional addition of $50 \mu \mathrm{l}$ per well of media in 24 well plates to prevent evaporation.

\section{Immunostaining}

Prior to treatment with prodomain, the 18-21 DIV mature neurons were starved in a pre-warmed Neurobasal media supplemented with $0.5 \%$ glucose. Val or Met or His40Lys mutant prodomains were added to the neurons, incubated at a final concentration of $10 \mathrm{ng} \mathrm{ml}{ }^{-1}$ for 1 hour at $37^{\circ} \mathrm{C}$, maintained at $5 \% \mathrm{CO}_{2}$. Following the treatment, neurons were quickly washed in warm $1 \times$ HBSS and immediately fixed with $4 \%$ paraformaldehyde $/ 4 \%$ glucose in $1 \times$ PBS for $15 \mathrm{~min}$. For immunostaining, the cells were permeabilized for 15 minutes with $0.1 \%$ Triton in $1 \times$ PBS containing 5\% FBS for blocking and stained for 15 minutes with Alexa Fluor 546 phalloidin (Life Technologies, Thermo-Fisher Scientific) at room temperature to demarcate actin enriched dendritic spines and outline neuronal morphology. Following staining procedure, neurons were rinsed in $1 \times$ PBS and coverslips mounted on the slides using ProLong Gold antifade reagent (Invitrogen).

\section{Antibodies}

The following primary antibodies were used: chicken polyclonal antiMAP2 (Abcam) to mark dendritic segments with anti-chicken $405 \mathrm{~nm}$ fluorescent DyLight (Jackson ImmunoResearch Laboratories, West Grove, PA, USA). Alexa Fluor 546 phalloidin (Life Technologies, Thermo Fisher Scientific) was used to demarcate actin enriched dendritic spines and the contour of neuronal morphology.

\section{Imaging}

The neurons were imaged using Structured Illumination Microscope (N-SIM) Nikon Eclipse Ti (Nikon Instruments Inc., Melville, NY, USA) using 100× Apo TIRF lens with 1.49 N.A. (Nikon Instruments Inc.) and Andor iXon3 DU-897E EMCCD camera (Andor Technology Ltd, Belfast, UK) using $10 \mathrm{MHz}, 14$-bit, conversion gain of $2.4 \times$ or $5 \times$ and $50 \%$ laser. Exposure times were customized to obtain 4000 maximum counts histogram values for red channel. ${ }^{15}$ Super resolution images were generated from illumination pattern at three angles and in five phases generating 15-image $Z$-stacks. Acquired images were reconstructed using NIS-Elements software 4.20 with N-SIM analysis plug-in (Nikon Elements). Reconstruction parameters (auto structured illumination contrast, 1.00 apodization filter parameter, 0.05 width of 3D-SIM filter) were kept consistent to generate the best Fourier transforms to visualize thin spines. ${ }^{15}$ The thin and mushroom spines were counted by the experimenter blinded to the conditions.

\section{Results}

BDNF and it prodomain are highly expressed in diverse brain regions, such as the hippocampus, which are known to have high concentrations of $\mathrm{Zn}^{2+}$, stored in vesicles. In hippocampal neurons, secretion of mature BDNF, prodomain and $\mathrm{Zn}^{2+}$ occur upon neuronal depolarization. Prior studies have identified $\mathrm{Zn}^{2+}$ binding interactions with the $\mathrm{N}$-terminus of mature $\mathrm{BDNF},{ }^{31}$ however the $\mathrm{Zn}^{2+}$ binding to the co-secreted prodomain has never been explored. This is of particular interest, since the Val66 and Met66 prodomain are exposed to high concentrations of this metal and could impact its structure and/or function.

\section{Zinc interacts with prodomain sites at His40, His65 and Glu111}

To characterize the interaction of $\mathrm{Zn}^{2+}$ with the intrinsically disordered prodomain isoforms we use heteronuclear NMR analysis to identify the individual residues that undergo association and structural change. To identify the specific prodomain residues impacted by $\mathrm{Zn}$ binding we have transferring our prior backbone heteronuclear NMR resonance assignments to conditions suitable for $\mathrm{Zn}$ titration analysis. ${ }^{23}$ The specific backbone $\mathrm{H}^{\mathrm{N}}{ }_{\mathrm{i}}$ and $\mathrm{N}_{\mathrm{i}}$, resonance assignments for the full length prodomain provide sensitive indicators that are affected by changes in chemical environment and dynamic motions. Addition of sub-stoichiometric concentrations of $\mathrm{Zn}^{2+}$ to the prodomains resulted in NMR spectral shifts and peak intensity changes in both Val66 and Met66 isoforms, indicating rapid prodomain- $\mathrm{Zn}^{2+}$ equilibrium kinetics, (Fig. 2 and Fig. S1A, B, ESI $\dagger$ ). Both isoforms display signal changes centered on residues His40, His65 and Glu111 (Fig. 2). Both His and to a lesser degree Glu residues are recognized for a propensity to associate with $\mathrm{Zn}^{2+}$. The residues impacted upon addition of $\mathrm{Zn}^{2+}$ are more extensive in the Met66 prodomain impacting 49 residues, compared to 24 residues in the Val66 prodomain under the same conditions (Fig. 2E). The Met66 prodomain displays greater changes in neighboring His40 (residues 37-50), His65 (residues 57-79), and Glu111 (residues 104-119), as compared to the more limited differences observed in the Val66 prodomain (residues 40-49, residues 60-77 and residues 111-112 of the Val66 prodomain) (Fig. 2E). Our NMR results indicate that the Met66 prodomain is significantly more responsive to $\mathrm{Zn}^{2+}$ binding than the Val66 isoform.

\section{BDNF Val66 and Met66 prodomains preferentially bind $\mathrm{Zn}^{2+}$}

Divalent cations $\mathrm{Ca}^{2+}, \mathrm{Mg}^{2+}$ and $\mathrm{Zn}^{2+}$ are all dynamically regulated within the synaptic cleft, available to interact with 

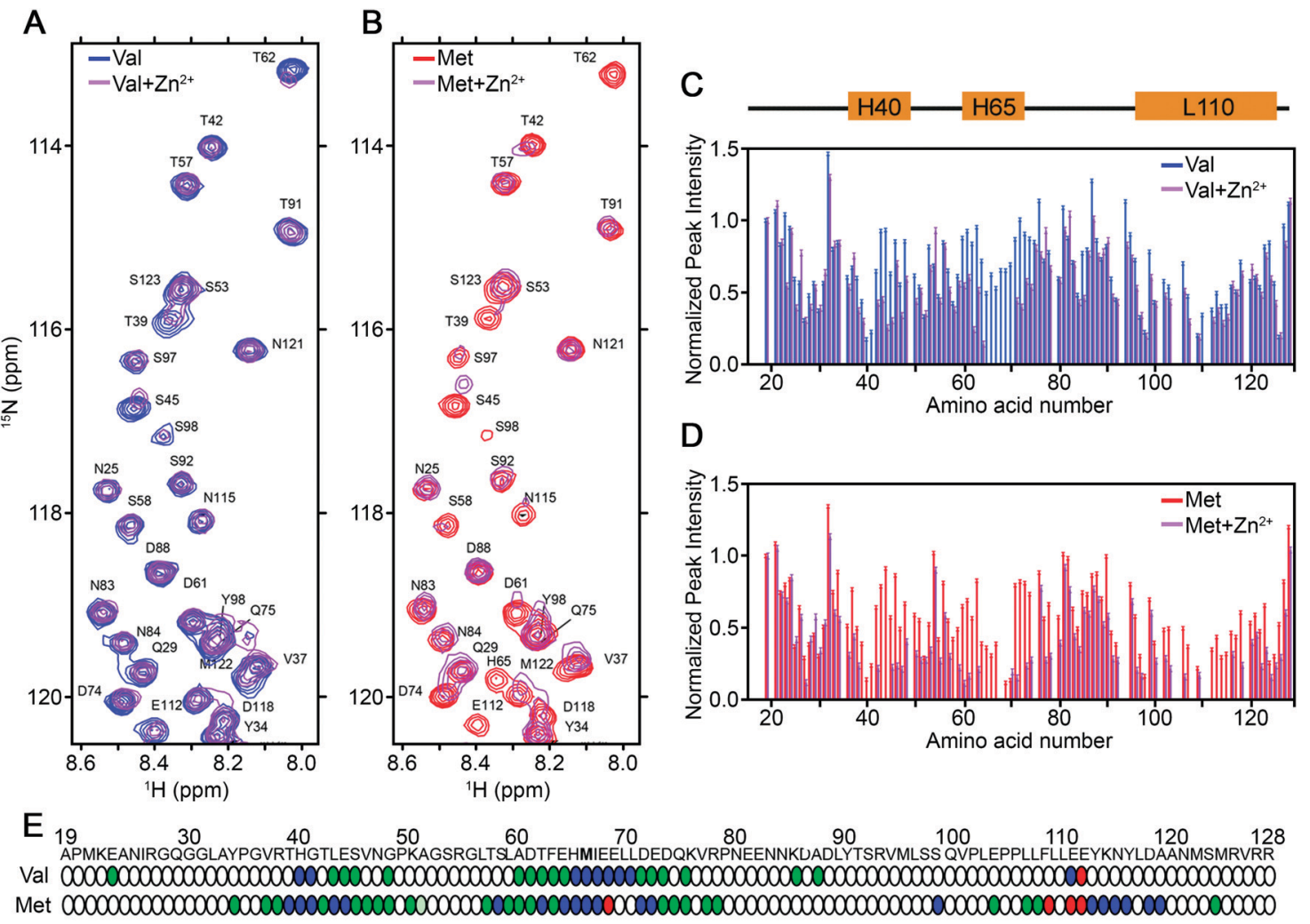

0 Intensity unassigned or overlapping

OIntensity lost upon $\mathrm{Zn}^{2+}$ binding O Intensity weak upon $\mathrm{Zn}^{2+}$ binding

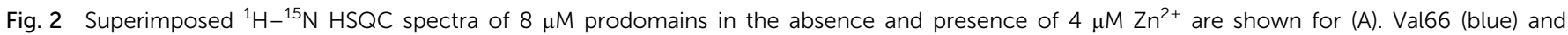
Val66 $+\mathrm{Zn}^{2+}$ (purple) and (B). Met66 (red) with Met66 $+\mathrm{Zn}^{2+}$ (purple). (C and D) A schematic centered at His40, His65 and Leu110 is shown above to provided reference. Addition of sub-stoichiometric $\mathrm{Zn}^{2+}$ results in significant attenuation of peak intensity at specific residues. The peak intensities for Val66 and Met66 were normalized to adjacent $\mathrm{N}$ - and $\mathrm{C}$-terminal residues which remain unperturbed by isoform variation and $\mathrm{Zn}^{2+}$ addition. The peak intensities significantly vary under native conditions for both (C) Val66 (light-blue) and (D) Met66 (light-red) in these three regions, and undergo significant reductions intensity upon $\mathrm{Zn}^{2+}$ binding shown for Val66 (blue) and Met66 (red). (E) A summary diagram of the prodomain sequence map regions of significant $\mathrm{Zn}^{2+}$ induced peak intensity changes based on moderate or complete intensity loss for Val (top) and Met (bottom), indicate three predominant regions centered neighboring histidine residues His40, His65 and hydrophobic region L110.

prodomain. ${ }^{32}$ Using simple turbidity analysis to assess cation mediated particle formation, we observed significant UV turbidity changes upon addition of physiologically relevant amount of $\mathrm{Zn}^{2+}$ to prodomain (Fig. 3). Higher levels of turbidity were consistently detected for Met66 as compared to the Val66 prodomain, indicating the presence of more abundant and/or larger particles on average. In contrast, turbidity changes were not detected upon addition of significantly high concentrations of $\mathrm{Ca}^{2+}$ or $\mathrm{Mg}^{2+}$ to the Val66 or Met66 prodomain, applied either individually (Fig. 3C and D) or together at physiologically relevant concentrations (Fig. S3A and B, ESI $\dagger$ ). These results strongly suggest that prodomain binding, and particulate assembly is specific for $\mathrm{Zn}^{+2}$. Under limiting prodomain concentrations, $\mathrm{Zn}^{2+}$ association displays sigmoidal kinetics, suggesting an initiation-propagation mechanism that favors more rapid assembly of the Met66 isoform, as compared to the Val66 prodomain (Fig. S3C and D, ESI $\dagger$ ). Furthermore, we observe $\mathrm{Zn}^{2+}$ association with the Met66 and Val66 prodomains in the setting of millimolar concentrations of $\mathrm{Ca}^{2+}$ and $\mathrm{Mg}^{2+}$, reflecting conditions present in vivo, indicating that divalent ions abundant within the synapse do not compete with $\mathrm{Zn}^{2+}$
(Fig. S3A and B, ESI $\dagger$ ). $\mathrm{Zn}^{2+}$ mediated particulates formed were reversible upon dilution (Fig. 3B), with slower kinetics of disassembly consistently observed for Met66 prodomain $\left(0.83 \pm 0.02 \mathrm{~min}^{-1}\right)$ as compared to the Val66 prodomain which exhibits bi-exponential dissociation rates with fast $(9.6 \pm$ $\left.0.4 \mathrm{~min}^{-1}\right)$ and slow $\left(0.88 \pm 0.07 \mathrm{~min}^{-1}\right)$ components (Fig. 3B). Complete return to baseline is not achieved without addition of EDTA, suggesting that a fraction of the macroscopic population is resistant to dissociation. Attempts to identify high affinity (nanomolar) prodomain-Zn interaction by mass spectrometry were unsuccessful, suggesting dissociation during ionization and gas phase analysis, due to weaker, reversible, micromolar $\mathrm{Zn}^{2+}$ binding affinity. Furthermore, diagnostic tests for amyloid binding via Congo red display no characteristic red shifts, indicating an absence of amyloid structure ${ }^{33}$ (Fig. S3E and F, ESI $\dagger$ ). Collectively this data demonstrates that $\mathrm{Zn}^{2+}$ interactions with the Met66 or Val66 prodomain to induce isoform specific differences in macromolecular structure that are largely reversible yet kinetically distinct, suggesting that Met66-Zn aggregates are structurally different from Val66-Zn aggregates in both assembly and dissociation. 
A

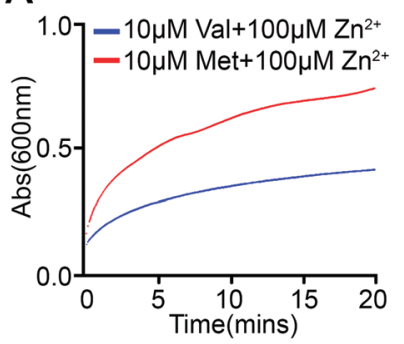

C

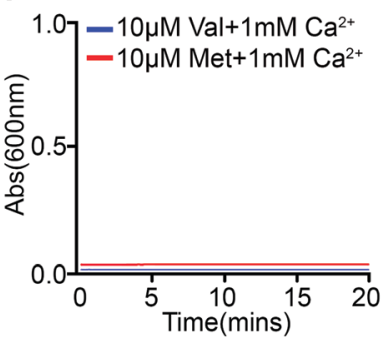

B

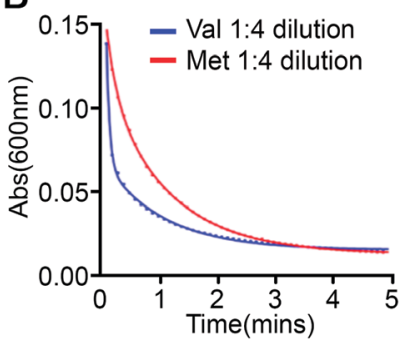

D

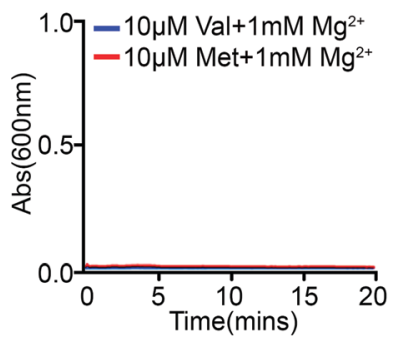

Fig. 3 Turbidity changes monitored at $600 \mathrm{~nm}$ identifies the formation of aggregates in the presence of $10 \mu \mathrm{M}$ Val66 and Met66 prodomains in

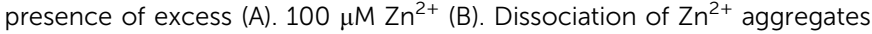

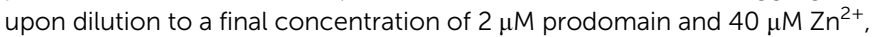
prodomain and $\mathrm{Zn}^{2+}$ concentrations that fail to develop turbidity.

\section{Biophysical differences in the interaction of $\mathrm{Zn}^{2+}$ with Val66 and Met66 prodomains}

To investigate the thermodynamic differences upon the interaction of $\mathrm{Zn}^{2+}$ with the Met66 and Val66 prodomains, we used isothermal titration calorimetry (ITC) (Fig. 4). The ITC titration curves can be fitted to a single broad transition with apparent micromolar affinity $\left(K_{\mathrm{D}}=12.5 \mu \mathrm{M}\right.$ and $\left.23.8 \mu \mathrm{M}\right)$ for Val66 and Met66 isoforms respectively. These $\mathrm{Zn}^{2+}$ titrations are dominated by large endothermic changes that are qualitatively similar in magnitude for both isoforms $\left(-T \Delta S=-44 \mathrm{~kJ} \mathrm{~mol}^{-1}\right)$, consistent with a hydrophobically driven process (Fig. 4A), with unfavorable enthalpic contributions data provided in Table S1 (ESI $\dagger$ ). However, the specific residue changes observed by NMR (Fig. 2) identify multiple regions of the prodomain that are altered upon $\mathrm{Zn}^{2+}$ binding, strongly suggesting that the observed curve reflects an average of disparate sites involving inter- and/or intramolecular prodomain-Zn contacts.

\section{His40 is a critical residue for prodomain multimerization}

To better understand how $\mathrm{Zn}^{2+}$ binding affects the structure of the Met66 and Val66 prodomains, we mutated His40 to Lys to evaluate impact of $\mathrm{Zn}^{2+}$ binding (Fig. 4). We found that substitution of His40Lys entirely prevents $\mathrm{Zn}^{2+}$ driven turbidity changes at millimolar $\mathrm{Zn}^{2+}$ concentrations (Fig. 4C), indicating that His40 is required for $\mathrm{Zn}^{2+}$ mediated intermolecular contacts needed for macroscopic particle formation. The effects of His40Lys substitution were then evaluated by ITC, and reveal a multistate binding process upon addition of $\mathrm{Zn}^{2+}$, not discernable with the native prodomains, due to $\mathrm{Zn}^{2+}$ driven aggregate association that obscures interpretation. Both His40Lys mutants Val66 and Met66 prodomains display distinctive biphasic ITC transitions (Fig. 4B).
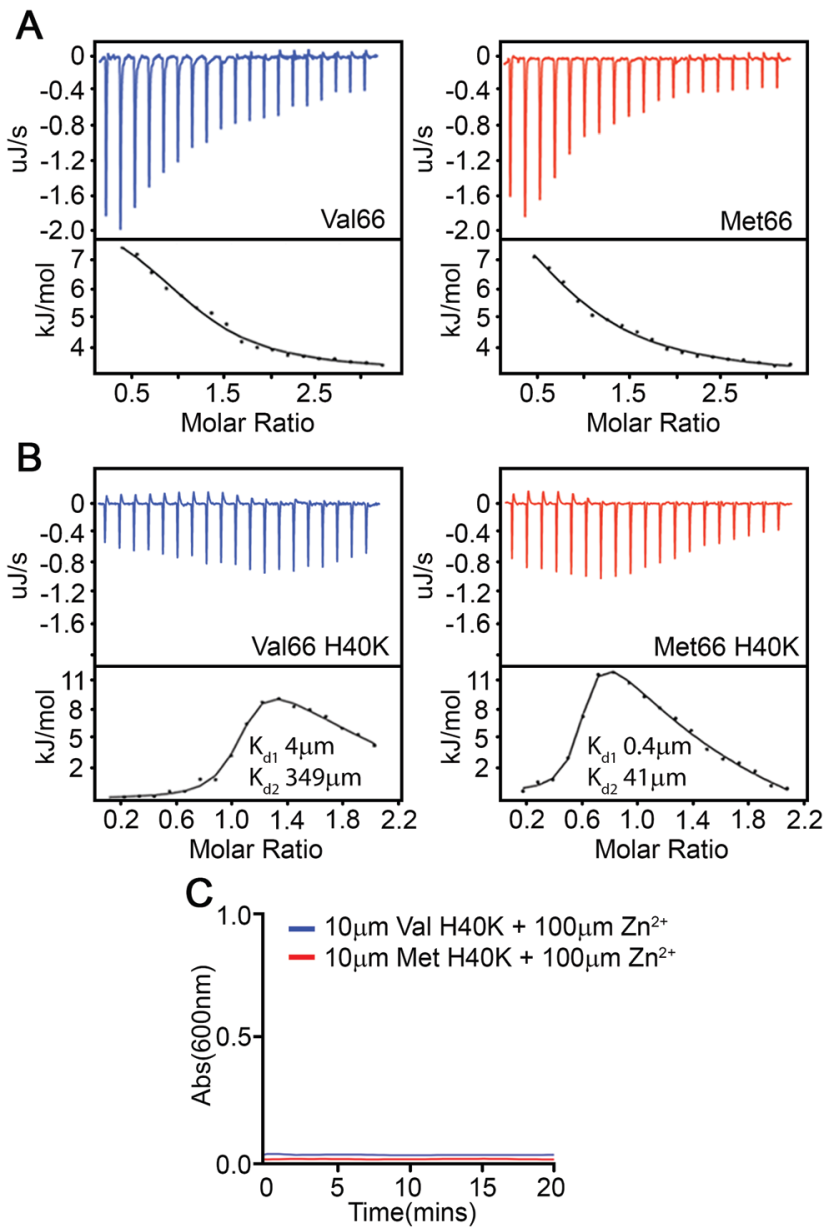

Fig. 4 BDNF prodomain- $\mathrm{Zn}^{2+}$ binding measurement. (A) ITC $\mathrm{ZnCl}_{2}$ titration profile of Val6 (left panel), Met66 (right panel) monitoring $Z \mathrm{n}^{2+}$ binding upon injection of $\mathrm{Zn}^{2+}$ aliquots to $30 \mathrm{mM}$ prodomain. The ITC experiments indicate that $\mathrm{Zn}^{2+}$ binding affinity to full length $\mathrm{Val}$ and Met prodomains yield similar affinities (Table S1, ESI $\dagger$ ). (B) Whereas the Val-H4OK (left panel) and Met-H4OK (right panel) mutants reveal underlying differences in $\mathrm{Zn}^{2+}$ binding affinity in the absence of His40. Note that Met H4OK mutations display no apparent aggregate formation at elevated zinc concentrations, whereas the Met $\mathrm{H} 65 \mathrm{~K}$ mutation retains aggregation characteristics complicating ITC analysis.

The Met66-His40Lys prodomain displays a strong initial enthalpic transition with 10-fold higher affinity $\left(K_{\mathrm{d}_{1}}=0.4 \pm 0.2 \mu \mathrm{M}\right)$ at $2: 1$ prodomain: $\mathrm{Zn}^{2+}$ stoichiometry $\left(n_{1}=0.5 \pm 0.08\right)$. This initial transition is followed by a weaker secondary transition $\left(K_{\mathrm{d}_{2}}=\right.$ $41 \pm 36 \mu \mathrm{M})$. The Val66-His40Lys prodomain displays an initial transition with equimolar prodomain-Zn $\left(n_{1}=1.1 \pm 0.4\right)$, with lower affinity $\left(K_{\mathrm{d}_{1}}=4 \pm 6 \mu \mathrm{M}\right)$, and a very weak secondary interaction $\left(K_{\mathrm{d}_{2}}=347 \pm 565 \mu \mathrm{M}\right)$ (Table S1, ESI $\dagger$ ). Collectively, these results suggest that the Met66 substitution may alter the conformation impacting prodomain- $\mathrm{Zn}^{2+}$ affinity, resulting in a higher affinity $\mathrm{Zn}^{2+}$ association with Met66 prodomain compared to the Val66 prodomain.

\section{Zinc binding results in different macroscopic structures}

The differences in prodomain $\mathrm{Zn}^{2+}$ induced spectral changes and binding affinity prompted us to ask whether Met66 and 

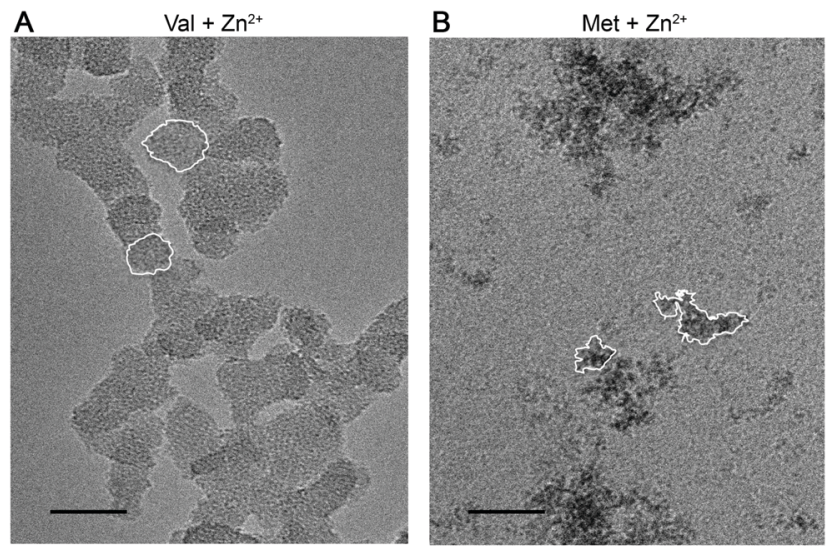

C

D

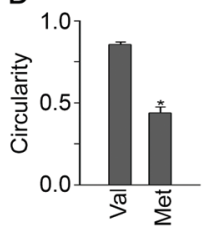

$\mathrm{E}$

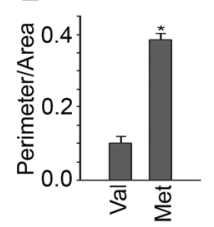

Fig. 5 Cryo-EM reveals isoform dependent differences upon $\mathrm{Zn}^{2+}$ bind-

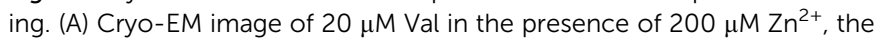
$\mathrm{Zn}^{2+}$ induced precipitate results in formation of uniform particles with a rounded appearance. (B) Identically prepared Met prodomain- $\mathrm{Zn}^{2+}$ results in aggregates that appear disordered and of varying size. Scale bar shown in (A and B), represent a $100 \mathrm{~nm}$ length. Representative particles are outlined in (A and B), for calculation of (C) area, (D) perimeter and (E) circularity. (C-E) The Val- $\mathrm{Zn}^{2+}$ structures display a greater degree of uniformity in comparison to the Met- $\mathrm{Zn}^{2+}$ aggregates, suggesting underlying isoform dependent differences in prodomain $-\mathrm{Zn}^{2+}$ interactions.

Val66 prodomain- $\mathrm{Zn}^{2+}$ complexes adopt different macroscopic forms. To analyze these structures, we employed cryo-EM imaging of the prodomain- $\mathrm{Zn}^{2+}$ complexes. Prodomain assemblies display strikingly different morphological appearances by cryo-EM (Fig. 5A and B). The Val66 multimers appear as uniformly shaped clusters of smaller spherical units. Analysis of $\mathrm{Zn}^{2+}-$ Val66 prodomain clusters reveal a similarity in particle size with a high degree of circularity and small perimeter to area ratios indicating a reduced complexity of shape (Fig. 5C-E). The smaller spherical units appear to be less than $10 \mathrm{~nm}$ in diameter, which form larger clusters range from 50-70 $\mathrm{nm}$ in size. In contrast, the $\mathrm{Zn}^{2+}$-Met66 prodomain multimers appear as irregularly shaped particulates of widely varying size, with reduced circularity and a larger perimeter/area ratio indicating a greater degree of rugosity. The gross difference in macromolecular morphology between $\mathrm{Zn}^{2+}$-associated Val66 and Met66 prodomains likely underscores differences in the residues of the prodomain exposed upon $\mathrm{Zn}^{2+}$ binding.

\section{The His40Lys mutant blocks Met66 prodomain gain of function}

Given the dramatic $\mathrm{Zn}^{2+}$-mediated changes in multimerization observed in the Met66 vs. Val66 prodomains and the impact of the His40Lys mutation, we investigated the effect of these proteins on cultured hippocampal neurons. Previous findings indicated that application of the Met66 prodomain but not the Val66 prodomain to mature hippocampal neuron cultures

results in the rapid disassembly of synaptic spines and actively eliminates synapses. ${ }^{6,15,34-36}$ In the prior study, the prodomains were exposed to $\mathrm{Zn}^{2+}$ which is present in the cell culture media. To directly test whether $\mathrm{Zn}^{2+}$ macromolecular association is required for acute negative remodeling of synaptic spines, we compared the bioactivity of Met66 or Val66 prodomains, to Met66 His40Lys or Val66 His40Lys prodomains that fail to associate into macroscopic structure.

To this end, we added recombinant Met66 His40Lys prodomain (10 $\mathrm{ng} \mathrm{ml^{-1 }}$ ), or Met66 prodomain $\left(10 \mathrm{ng} \mathrm{ml}^{-1}\right.$ ) or vehicle control to mature hippocampal neurons cultured in $\mathrm{Zn}^{2+}$ containing Neurobasal media (Fig. 6A). We conducted a detailed analysis of the effects of the Met66 prodomain on neuronal morphology, specifically examining mature mushroom spines, thin spines and total spines on dendrites using structured illumination microscopy (SIM). Upon addition of the Met prodomain, we observe a transition of the mature mushroom spines into thin/filopodia like protrusions, as demonstrated by a $\sim 60 \%$ decrease in mushroom spines and an equal increase in thin spines within 1 hour, without an overall change in spine density (Fig. 6B-D) and consistent with prior studies. ${ }^{15}$ In contrast, no acute morphological or density changes were observed in neurons treated with the His40Lys Met66 prodomain mutants (Fig. 6B). No effects of synaptic remodeling were observed following treatment with the Val66 prodomain, consistent with prior results, ${ }^{6,15}$ or with His40Lys Val66 prodomain. These results suggest that Met66 prodomain bioactivity is dependent on interactions of His40 with $\mathrm{Zn}^{+2}$.

\section{Discussion}

Both the BDNF prodomain and $\mathrm{Zn}^{2+}$ are secreted into the synaptic cleft in response to repeated stimulation of hippocampal neurons. ${ }^{16,37}$ Both BDNF isoforms (including the prodomain) and $\mathrm{Zn}^{2+}$ are regionally restricted within the brain, with chelatable $\mathrm{Zn}^{2+}$ levels regulated by the expression of zinc transporters. ${ }^{38}$ Indeed, BDNF is highly expressed in the hippocampus and amygdala, ${ }^{39}$ regions that exhibit the highest concentrations of chelatable $\mathrm{Zn}^{2+}$ in the central nervous system (CNS). ${ }^{40}$ Prolonged neuronal depolarization induces the release of $\mathrm{Zn}^{2+}$ into the synaptic cleft, as well as the release of mature BDNF and the prodomain from dense core vesicles. ${ }^{16}$ Stimulated secretion of $\mathrm{Zn}^{2+}$ in hippocampal tissues has been calculated to approach concentrations of $30 \mu \mathrm{M}$ or more in the region of mossy fiber input to the CA1 region of the hippocampus. ${ }^{41,42}$ This concentration of $\mathrm{Zn}^{2+}$, in the presence of secreted prodomain, could be utilized to promote the formation of distinct prodomain oligomeric species.

Our prior work demonstrates that the Met66 prodomain isoform elicits morphological changes in neuronal growth cones and dendritic spines through interactions with the SorCS2 receptor, whereas the Val66 isoform was shown to be inert. Furthermore, the Met66 isoform negatively impacts the circuits associated with memory and anxiety disorders ${ }^{43-46}$ and has recently been implicated as an relevant target in Alzheimer's disease. ${ }^{47,48}$ 

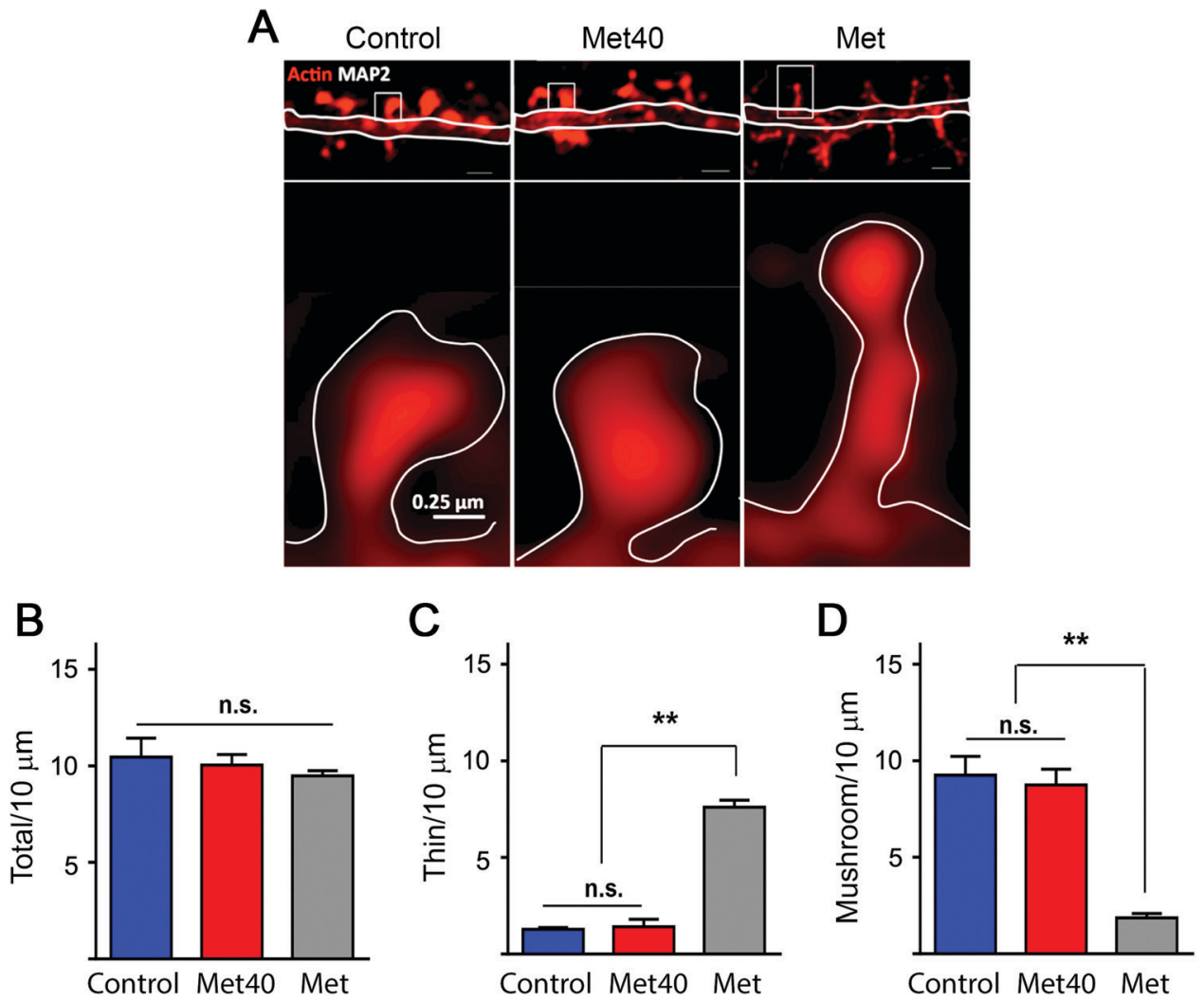

Fig. 6 BDNF Met prodomain, but not Met-His40Lys, leads to acute dendritic spine changes. (A) DIV20 neurons, visualized by structured illumination microscopy, using actin binding phalloidin-alexa546 and MAP2. (B) Quantitation of spine number; (C) thin spine phenotype; (D) mushroom phenotype; analyzing the effects of the Met (Met) prodomain vs. the Met-His40Lys (Met 40). Error bars are given for $n=10$ neurons/condition. ${ }^{* *} p<0.001$ ( $t$ test).

Our observation that the Val66 and Met66 prodomains differentially interact with $\mathrm{Zn}^{2+}$ at physiological concentrations, together with our findings that the Met66 bioactivity is blocked by selective mutation of His40 points to a potential role for $\mathrm{Zn}^{2+}$ binding in Met66 in vivo bioactivity.

Recent computational studies of the BDNF prodomain by Lohia et al. $^{49}$ evaluated differential intramolecular interactions of the Met66 or Val66 prodomains in the apo state. In their computational modeling study, the Met66 prodomain isoform exhibited an enhanced intramolecular association between Met66 with nonlocal C-terminal residues including Met95 as well as local (Phe63) and nonlocal aromatic residues (Phe108, Tyr113), as compared to the Val66 isoform which displays significantly weaker long-range intramolecular contacts between Val66 and C-terminal residues. Their modeling results are consistent with our observations of the Met66 and Val66 prodomains in the absence of $\mathrm{Zn}^{2+}$. Specifically, NMR analysis of the 66-region and C-terminal regions show evidence of chemical exchange dynamics, as monitored by NMR relaxation measurements. The impact of chemical exchange is significantly more prevalent in the Met66 prodomain as compared to the Val66 prodomain (Fig. S4, ESI†). Furthermore, both prodomain isoforms in the apo state display concentration dependent loss in NMR spectral intensities due to chemical exchange localized in the 66-region and the C-terminal, 111-region. In addition, we observe concentration dependent changes of the apo prodomains by NMR diffusion indicate a greater degree compaction and concentration dependent intermolecular association of the Met66 prodomain, as compared to the Val66 isoform (Fig. S5, ESI $\dagger$ ). Our experimental studies are consistent with Lohia's model of Met66 prodomain interactions where the Met66-region and C-terminal regions enhance intramolecular regional self-association.

The differences in the Met66 and Val66 prodomain $\mathrm{Zn}^{2+}$ binding and multimerization are critically dependent upon residue His40. In the apo-state both isoforms display dynamic and concentration dependent changes that primarily effect the 66- and 111-regions of the prodomain, whereas the His40 residues are largely unperturbed. Our prior examination of prodomain-SorCS2 interactions in the apo state indicates that the 66-region and the C-terminal 111-region are the regions involved in SorCS2 binding. The His40 region has shown no prior involvement in binding to SorCS2 or its homologous receptor, Sortilin. ${ }^{6,50}$ The importance of $\mathrm{Zn}^{2+}$ mediated oligomerization is highlighted by our mutational studies which indicate that residue His40 is essential for intermolecular macroscopic association in both Val66 and Met66 isoforms. ITC analysis indicates similar $\mathrm{Zn}^{2+}$ titration energetics for native Val66 and Met66 prodomains, dominated by entropic contributions (Fig. 4A). However, upon His40Lys mutation, two distinct underlying transitions are revealed. The mutant, His40Lys-Met66 displays an initial enthalpically driven interaction upon $\mathrm{Zn}^{2+}$ binding, that is of higher affinity as compared 
to His40Lys-Val66. This initial transition is followed by a secondary weaker endothermic transition seen in both isoforms (Fig. 4B). NMR changes upon $\mathrm{Zn}^{2+}$ addition that simultaneously occur in both Met66 and C-terminal regions of prodomain. The structure conferred by Met66, enhances $\mathrm{Zn}^{2+}$ binding and association with the C-terminal portion of the prodomain in comparison to Val66. Collectively these interactions directly impact prodomain- $\mathrm{Zn}^{2+}$ macroscopic structure.

Prodomain- $\mathrm{Zn}^{2+}$ binding leads to distinct macroscopic differences between Val66 and Met66 prodomain- $\mathrm{Zn}^{2+}$ assemblies (Fig. 5A and B). The Val66 prodomain- $\mathrm{Zn}^{2+}$ assemblies adopt more uniformly sized particles in the presence of $\mathrm{Zn}^{2+}$, and dissociate rapidly compared to the Met66 prodomain (Fig. 5A). In contrast, $\mathrm{Zn}^{2+}$ binding to Met66 prodomain results in irregular assemblies as shown by cryo-EM (Fig. 5B). Differences upon addition of $\mathrm{Zn}^{2+}$ are seen in the greater loss in Met66 NMR signal intensities, surrounding residue 66 , as well as a modest increase Met66 helical structure shown by circular dichroism (CD) (Fig. S2, $\mathrm{ESI} \dagger$ ) and a greater Met66- $\mathrm{Zn}^{2+}$ dissociation timeframe as assessed by turbidity analysis. We hypothesize that Met66 isoform aggregates can provide multivalent interactions that enable effective SorCS2 clustering to initiate negative synaptic remodeling. It is well established that $\mathrm{Zn}^{2+}$ can induce conformational changes in other proteins related to neurodegenerative diseases. Binding to $\mathrm{Zn}^{2+}$ structurally impacts a number of neurodegenerationrelated proteins leading to oligomerization or protein aggregation in vitro; this includes the intrinsically disordered proteins TDP- $43,{ }^{51}$ tau, ${ }^{52} \alpha$-synuclein, ${ }^{53}$ and $A \beta .^{54-56}$ Ordered aggregation and assembly events, such as fibrils or repeating high-order assemblies are known to initiate signaling complexes utilized in normal physiological responses. ${ }^{28,57}$ In contrast, misfolded, oligomeric pathogenic and nonpathogenic proteins or even small organic molecules forming colloidal aggregates can provoke interactions that often prove cytotoxic. ${ }^{58-61}$

Promiscuous interactions in the extracellular spaces could potentially disrupt synaptic signaling and channel proteins. The most likely prodomain interaction in this context is SorCS2, that exists as a dimer, as assessed by X-ray crystallography and negatively stained electron microscopy. ${ }^{62}$ The regions of the prodomain surrounding the Val66Met polymorphism directly interact with SorCS2 in the absence of $\mathrm{Zn}^{2+}$, as previously assessed by NMR using a truncated form of the Met66 or Val66 prodomain. ${ }^{6}$ However, the regions in SorCS2 that interact with the prodomain have not been defined, nor has the mechanism by which SorCS2 interacts with the $\mathrm{p} 75^{\mathrm{NTR}}$ co-receptor, as both receptors are required for growth cone retraction and synaptic remodeling. Analysis of the direct interactions of $\mathrm{Zn}^{2+}$-prodomain oligomers with dimeric SorCS2, and with $\mathrm{p} 75^{\mathrm{NTR}}$, will require additional experimentation.

\section{Author contributions}

J. W., H. B. and A. A. prepared protein for biological and biophysical analysis. J. W, and C. B. performed NMR data collection and analysis. A. A, W. J. R. and C. B. performed EM data collection and analysis. J. W. and C. B. performed ITC analysis. A. A., J. W., H. B., and D. W. performed CD. measurements. J. W., A. A., D. W. and H. B. performed light scattering analysis. T. N. and J. D., performed mass spectrometry and binding analysis. J. G. performed neuronal SIM analysis. C. B., B. L. H., and F. S. L. supervised analysis and designed experiments. C. B., et al. wrote the paper, all co-authors contributed to editing.

\section{Conflicts of interest}

The authors declare no competing interests.

\section{Acknowledgements}

We thank Roshelle Smith for assistance in protein expression and purification. The authors also thank Dr Olga Boudker for help in recording and interpretation of ITC data. We thank Dr Greg Petsko for helpful insights and discussions on metal binding and protein analysis. This work was supported by NIH R01 NS052819 (to F. S. L. and B. L. H.), NIH NS050276 and NIH Shared Instrumentation Grant S10 RR027990 (to T. A. N.) and NIH R21NS090322-01A1 NIH S10 RR023694, NIH S10 OD016320 (to C. B.). Parts of this work were carried out at the New York Structural Biology Center (NYSBC), NYSTAR Facility. Some of this work was performed at the Simons Electron Microscopy Center at the New York Structural Biology Center that is supported by a grant from the Simons Foundation (Grant Number: 349247) with additional support from: NIH S10 OD019994-01, the Agouron Institute (Grant Number: F00316), NIH S10 RR029300-01, NIH S10 RR017291-01, NYSTAR, and NIH C06 RR017528-01-CEM.

\section{References}

1 B. Lu, P. T. Pang and N. H. Woo, The yin and yang of neurotrophin action, Nat. Rev. Neurosci., 2005, 6, 603-614.

2 L. F. Reichardt, Neurotrophin-regulated signalling pathways, Philos. Trans. R. Soc., B, 2006, 361, 1545-1564.

3 C. R. Bramham, P. F. Worley, M. J. Moore and J. F. Guzowski, The immediate early gene arc/arg3.1: regulation, mechanisms, and function, J. Neurosci., 2008, 28, 11760-11767.

4 S. Cohen and M. E. Greenberg, Communication between the synapse and the nucleus in neuronal development, plasticity, and disease, Annu. Rev. Cell Dev. Biol., 2008, 24, 183-209.

5 K. K. Teng, S. Felice, T. Kim and B. L. Hempstead, Understanding proneurotrophin actions: recent advances and challenges, Dev. Neurobiol., 2010, 70, 350-359.

6 A. Anastasia, K. Deinhardt, M. V. Chao, N. E. Will, K. Irmady, F. S. Lee, B. L. Hempstead and C. Bracken, Val66Met polymorphism of BDNF alters prodomain structure to induce neuronal growth cone retraction, Nat. Commun., 2013, 4, 2490.

7 J. Yang, L. C. Harte-Hargrove, C. J. Siao, T. Marinic, R. Clarke, Q. Ma, D. Jing, J. J. Lafrancois, K. G. Bath, W. Mark, D. Ballon, 
F. S. Lee, H. E. Scharfman and B. L. Hempstead, proBDNF negatively regulates neuronal remodeling, synaptic transmission, and synaptic plasticity in hippocampus, Cell Rep., 2014, 7, 796-806.

8 H. K. Teng, K. K. Teng, R. Lee, S. Wright, S. Tevar, R. D. Almeida, P. Kermani, R. Torkin, Z. Y. Chen, F. S. Lee, R. T. Kraemer, A. Nykjaer and B. L. Hempstead, ProBDNF induces neuronal apoptosis via activation of a receptor complex of p75NTR and sortilin, J. Neurosci., 2005, 25, 5455-5463.

9 M. F. Egan, M. Kojima, J. H. Callicott, T. E. Goldberg, B. S. Kolachana, A. Bertolino, E. Zaitsev, B. Gold, D. Goldman, M. Dean, B. Lu and D. R. Weinberger, The BDNF val66met polymorphism affects activity-dependent secretion of BDNF and human memory and hippocampal function, Cell, 2003, 112, 257-269.

10 H. Frielingsdorf, K. G. Bath, F. Soliman, J. Difede, B. J. Casey and F. S. Lee, Variant brain-derived neurotrophic factor Val66Met endophenotypes: implications for posttraumatic stress disorder, Ann. N. Y. Acad. Sci., 2010, 1208, 150-157.

11 I. Dincheva, C. E. Glatt and F. S. Lee, Impact of the BDNF Val66Met polymorphism on cognition: implications for behavioral genetics, The Neuroscientist: a review journal bringing neurobiology, neurology and psychiatry, 2012, 18, 439-451.

12 F. Soliman, C. E. Glatt, K. G. Bath, L. Levita, R. M. Jones, S. S. Pattwell, D. Jing, N. Tottenham, D. Amso, L. H. Somerville, H. U. Voss, G. Glover, D. J. Ballon, C. Liston, T. Teslovich, T. Van Kempen, F. S. Lee and B. J. Casey, A Genetic Variant BDNF Polymorphism Alters Extinction Learning in Both Mouse and Human, Science, 2010, 327, 863-866.

13 M. Verhagen, A. van der Meij, P. A. van Deurzen, J. G. Janzing, A. Arias-Vasquez, J. K. Buitelaar and B. Franke, Meta-analysis of the BDNF Val66Met polymorphism in major depressive disorder: effects of gender and ethnicity, Mol. Psychiatry, 2010, 15, 260-271.

14 T. Hajek, M. Kopecek and C. Höschl, Reduced hippocampal volumes in healthy carriers of brain-derived neurotrophic factor Val66Met polymorphism: meta-analysis, The world journal of biological psychiatry: the official journal of the World Federation of Societies of Biological Psychiatry, 2012, 13, 178-187.

15 J. I. Giza, J. Kim, H. C. Meyer, A. Anastasia, I. Dincheva, C. I. Zheng, K. Lopez, H. Bains, J. Yang, C. Bracken, C. Liston, D. Jing, B. L. Hempstead and F. S. Lee, The BDNF Val66Met Prodomain Disassembles Dendritic Spines Altering Fear Extinction Circuitry and Behavior, Neuron, 2018, 99(163-178), e166.

16 S. Dieni, T. Matsumoto, M. Dekkers, S. Rauskolb, M. S. Ionescu, R. Deogracias, E. D. Gundelfinger, M. Kojima, S. Nestel, M. Frotscher and Y.-A. Barde, BDNF and its propeptide are stored in presynaptic dense core vesicles in brain neurons, J. Cell Biol., 2012, 196, 775-788.

17 S. L. Sensi, P. Paoletti, J.-Y. Koh, E. Aizenman, A. I. Bush and M. Hershfinkel, The Neurophysiology and Pathology of Brain Zinc, J. Neurosci., 2011, 31, 16076-16085.
18 R. Llinas, M. Sugimori and R. B. Silver, Microdomains of high calcium concentration in a presynaptic terminal, Science, 1992, 256, 677-679.

19 R. Schneggenburger and E. Neher, Intracellular calcium dependence of transmitter release rates at a fast central synapse, Nature, 2000, 406, 889-893.

20 A. Romani and A. Scarpa, Regulation of cell magnesium, Arch. Biochem. Biophys., 1992, 298, 1-12.

21 E. Mossessova and C. D. Lima, Ulp1-SUMO crystal structure and genetic analysis reveal conserved interactions and a regulatory element essential for cell growth in yeast, Mol. Cell, 2000, 5, 865-876.

22 J. Marley, M. Lu and C. Bracken, A method for efficient isotopic labeling of recombinant proteins, J. Biomol. NMR, 2001, 20, 71-75.

23 J. Wang, H. Bains, A. Anastasia and C. Bracken, NMR backbone resonance assignments of the prodomain variants of BDNF in the urea denatured state, Biomol NMR Assign, 2018, 12, 43-45.

24 F. Delaglio, S. Grzesiek, G. W. Vuister, G. Zhu, J. Pfeifer and A. Bax, NMRPipe: a multidimensional spectral processing system based on UNIX pipes, J. Biomol. NMR, 1995, 6, 277-293.

25 W. Lee, M. Tonelli and J. L. Markley, NMRFAM-SPARKY: enhanced software for biomolecular NMR spectroscopy, Bioinformatics, 2015, 31, 1325-1327.

26 J. M. Kneller, M. Lu and C. Bracken, An effective method for the discrimination of motional anisotropy and chemical exchange, J. Am. Chem. Soc., 2002, 124, 1852-1853.

27 W. Cao, C. Bracken, N. R. Kallenbach and M. Lu, Helix formation and the unfolded state of a 52-residue helical protein, Protein Sci., 2004, 13, 177-189.

28 Q. Qiao, C. Yang, C. Zheng, L. Fontán, L. David, X. Yu, C. Bracken, M. Rosen, A. Melnick, E. H. Egelman and $\mathrm{H}$. Wu, Structural architecture of the CARMA1/Bcl10/MALT1 signalosome: nucleation-induced filamentous assembly, Mol. Cell, 2013, 51, 766-779.

29 S. B. Shin, R. D. Almeida, G. Gerona-Navarro, C. Bracken and S. R. Jaffrey, Assembling ligands in situ using bioorthogonal boronate ester synthesis, Chem. Biol., 2010, 17, 1171-1176.

30 D. K. Wilkins, S. B. Grimshaw, V. Receveur, C. M. Dobson, J. A. Jones and L. J. Smith, Hydrodynamic radii of native and denatured proteins measured by pulse field gradient NMR techniques, Biochemistry, 1999, 38, 16424-16431.

31 A. Travaglia, D. La Mendola, A. Magri, A. Pietropaolo, V. G. Nicoletti, G. Grasso, G. Malgieri, R. Fattorusso, C. Isernia and E. Rizzarelli, Zinc(II) interactions with brain-derived neurotrophic factor N-terminal peptide fragments: inorganic features and biological perspectives, Inorg. Chem., 2013, 52, 11075-11083.

32 R. A. Colvin, W. R. Holmes, C. P. Fontaine and W. Maret, Cytosolic zinc buffering and muffling: their role in intracellular zinc homeostasis, Metallomics, 2010, 2, 306-317.

33 W. E. Klunk, R. F. Jacob and R. P. Mason, Quantifying amyloid by congo red spectral shift assay, Methods Enzymol., 1999, 309, 285-305.

34 N. H. Woo, H. K. Teng, C. J. Siao, C. Chiaruttini, P. T. Pang, T. A. Milner, B. L. Hempstead and B. Lu, Activation of 
p75NTR by proBDNF facilitates hippocampal long-term depression, Nat. Neurosci., 2005, 8, 1069-1077.

35 M. Zagrebelsky, A. Holz, G. Dechant, Y. A. Barde, T. Bonhoeffer and M. Korte, The p75 neurotrophin receptor negatively modulates dendrite complexity and spine density in hippocampal neurons, J. Neurosci., 2005, 25, 9989-9999.

36 S. Glerup, D. Olsen, C. B. Vaegter, C. Gustafsen, S. S. Sjoegaard, G. Hermey, M. Kjolby, S. Molgaard, M. Ulrichsen, S. Boggild, S. Skeldal, A. N. Fjorback, J. R. Nyengaard, J. Jacobsen, D. Bender, C. R. Bjarkam, E. S. Sorensen, E. M. Fuchtbauer, G. Eichele, P. Madsen, T. E. Willnow, C. M. Petersen and A. Nykjaer, SorCS2 regulates dopaminergic wiring and is processed into an apoptotic two-chain receptor in peripheral glia, Neuron, 2014, 82, 1074-1087.

37 X. M. Xie and T. G. Smart, A physiological role for endogenous zinc in rat hippocampal synaptic neurotransmission, Nature, 1991, 349, 521-524.

38 A. Travaglia and D. La Mendola, Zinc Interactions With Brain-Derived Neurotrophic Factor and Related Peptide Fragments, Vitam. Horm., 2017, 104, 29-56.

39 W. C. Wetsel, R. M. Rodriguiz, J. Guillemot, E. Rousselet, R. Essalmani, I. H. Kim, J. C. Bryant, J. Marcinkiewicz, R. Desjardins, R. Day, D. B. Constam, A. Prat and N. G. Seidah, Disruption of the expression of the proprotein convertase PC7 reduces BDNF production and affects learning and memory in mice, Proc. Natl. Acad. Sci. U. S. A., 2013, 110, 17362-17367.

40 C. Sindreu and D. R. Storm, Modulation of neuronal signal transduction and memory formation by synaptic zinc, Front. Behav. Neurosci., 2011, 5, 68.

41 K. Vogt, J. Mellor, G. Tong and R. Nicoll, The actions of synaptically released zinc at hippocampal mossy fiber synapses, Neuron, 2000, 26, 187-196.

42 S. Ueno, M. Tsukamoto, T. Hirano, K. Kikuchi, M. K. Yamada, N. Nishiyama, T. Nagano, N. Matsuki and Y. Ikegaya, Mossy fiber $\mathrm{Zn}^{2+}$ spillover modulates heterosynaptic $N$-methyl-Daspartate receptor activity in hippocampal CA3 circuits, J. Cell Biol., 2002, 158, 215-220.

43 J. M. Gatt, C. B. Nemeroff, C. Dobson-Stone, R. H. Paul, R. A. Bryant, P. R. Schofield, E. Gordon, A. H. Kemp and L. M. Williams, Interactions between BDNF Val66Met polymorphism and early life stress predict brain and arousal pathways to syndromal depression and anxiety, Mol. Psychiatry, 2009, 14, 681-695.

44 B. Lu, G. Nagappan and Y. Lu, BDNF and synaptic plasticity, cognitive function, and dysfunction, Handb. Exp. Pharmacol., 2014, 220, 223-250.

45 H. Frielingsdorf, K. G. Bath, F. Soliman, J. Difede, B. J. Casey and F. S. Lee, Variant brain-derived neurotrophic factor Val66Met endophenotypes: implications for posttraumatic stress disorder, Ann. N. Y. Acad. Sci., 2010, 1208, 150-157.

46 F. Soliman, C. E. Glatt, K. G. Bath, L. Levita, R. M. Jones, S. S. Pattwell, D. Jing, N. Tottenham, D. Amso, L. H. Somerville, H. U. Voss, G. Glover, D. J. Ballon, C. Liston, T. Teslovich, T. Van Kempen, F. S. Lee and B. J. Casey, A genetic variant BDNF polymorphism alters extinction learning in both mouse and human, Science, 2010, 327, 863-866.
47 Y. Y. Lim, J. Hassenstab, C. Cruchaga, A. Goate, A. M. Fagan, T. L. Benzinger, P. Maruff, P. J. Snyder, C. L. Masters, R. Allegri, J. Chhatwal, M. R. Farlow, N. R. Graff-Radford, C. Laske, J. Levin, E. McDade, J. M. Ringman, M. Rossor, S. Salloway, P. R. Schofield, D. M. Holtzman, J. C. Morris, R. J. Bateman and N. Dominantly Inherited Alzheimer, BDNF Val66Met moderates memory impairment, hippocampal function and tau in preclinical autosomal dominant Alzheimer's disease, Brain, 2016, 139, 2766-2777.

48 E. A. Boots, S. A. Schultz, L. R. Clark, A. M. Racine, B. F. Darst, R. L. Koscik, C. M. Carlsson, C. L. Gallagher, K. J. Hogan, B. B. Bendlin, S. Asthana, M. A. Sager, B. P. Hermann, B. T. Christian, D. B. Dubal, C. D. Engelman, S. C. Johnson and O. C. Okonkwo, BDNF Val66Met predicts cognitive decline in the Wisconsin Registry for Alzheimer's Prevention, Neurology, 2017, 88, 2098-2106.

49 R. Lohia, R. Salari and G. Brannigan, Sequence specificity despite intrinsic disorder: how a disease-associated Val/Met polymorphism rearranges tertiary interactions in a long disordered protein, PLoS Comput. Biol., 2019, 15, e1007390.

50 Z. Y. Chen, A. Ieraci, H. Teng, H. Dall, C. X. Meng, D. G. Herrera, A. Nykjaer, B. L. Hempstead and F. S. Lee, Sortilin controls intracellular sorting of brain-derived neurotrophic factor to the regulated secretory pathway, J. Neurosci., 2005, 25, 6156-6166.

51 C. Garnier, F. Devred, D. Byrne, R. Puppo, A. Y. Roman, S. Malesinski, A. V. Golovin, R. Lebrun, N. N. Ninkina and P. O. Tsvetkov, Zinc binding to RNA recognition motif of TDP-43 induces the formation of amyloid-like aggregates, Sci. Rep., 2017, 7, 6812.

52 Y. Huang, Z. Wu, Y. Cao, M. Lang, B. Lu and B. Zhou, Zinc binding directly regulates tau toxicity independent of tau hyperphosphorylation, Cell Rep., 2014, 8, 831-842.

53 A. A. Valiente-Gabioud, V. Torres-Monserrat, L. MolinaRubino, A. Binolfi, C. Griesinger and C. O. Fernandez, Structural basis behind the interaction of $\mathrm{Zn}(2)(+)$ with the protein alpha-synuclein and the Abeta peptide: a comparative analysis, J. Inorg. Biochem., 2012, 117, 334-341.

54 B. Alies, A. Conte-Daban, S. Sayen, F. Collin, I. Kieffer, E. Guillon, P. Faller and C. Hureau, Zinc(II) Binding Site to the Amyloid-beta Peptide: Insights from Spectroscopic Studies with a Wide Series of Modified Peptides, Inorg. Chem., 2016, 55, 10499-10509.

55 M. A. Lovell, J. D. Robertson, W. J. Teesdale, J. L. Campbell and W. R. Markesbery, Copper, iron and zinc in Alzheimer's disease senile plaques, J. Neurol. Sci., 1998, 158, 47-52.

56 E. Atrian-Blasco, P. Gonzalez, A. Santoro, B. Alies, P. Faller and $\mathrm{C}$. Hureau, $\mathrm{Cu}$ and $\mathrm{Zn}$ coordination to amyloid peptides: from fascinating chemistry to debated pathological relevance, Coord. Chem. Rev., 2018, 375, 38-55.

$57 \mathrm{H}$. Wu and M. Fuxreiter, The Structure and Dynamics of Higher-Order Assemblies: Amyloids, Signalosomes, and Granules, Cell, 2016, 165, 1055-1066.

58 S. L. McGovern, E. Caselli, N. Grigorieff and B. K. Shoichet, A common mechanism underlying promiscuous inhibitors 
from virtual and high-throughput screening, J. Med. Chem., 2002, 45, 1712-1722.

59 F. U. Hartl, Protein Misfolding Diseases, Annu. Rev. Biochem., 2017, 86, 21-26.

60 T. P. Knowles, M. Vendruscolo and C. M. Dobson, The amyloid state and its association with protein misfolding diseases, Nat. Rev. Mol. Cell Biol., 2014, 15, 384-396.
61 S. Lee, M. C. Choi, K. Al Adem, S. Lukman and T. Y. Kim, Aggregation and Cellular Toxicity of Pathogenic or Nonpathogenic Proteins, Sci. Rep., 2020, 10, 5120.

62 D. Januliene, A. Manavalan, P. L. Ovesen, K. M. Pedersen, S. Thirup, A. Nykjaer and A. Moeller, Hidden Twins: SorCS Neuroreceptors Form Stable Dimers, J. Mol. Biol., 2017, 429, 2907-2917. 